\title{
Analyzing the effects of four submerged macrophytes with two contrasting architectures on zooplankton: A mesocosm experiment
}

\author{
Lei ZENG, ${ }^{1,2}$ Biyun LIU, ${ }^{1}$ Zhigang DAI, ${ }^{1}$ Qiaohong ZHOU,${ }^{1 *}$ Lingwei KONG, ${ }^{3}$ Yi ZHANG, ${ }^{1}$ Feng HE,${ }^{1 *}$ Zhenbin WU ${ }^{1}$ \\ ${ }^{1}$ State Key Laboratory of Freshwater Ecology and Biotechnology, Institute of Hydrobiology, the University of the Chinese Academy \\ of Sciences, Wuhan 430072; ${ }^{2}$ University of Chinese Academy of Sciences, Beijing 100049; ${ }^{3}$ Environmental Science Research \& \\ Design Institution of Zhejiang Province, Hangzhou 310007, China
}

*Corresponding authors: qhzhou@ihb.ac.cn; hefeng@ihb.ac.cn

\begin{abstract}
Increases in the structural complexity of submerged macrophytes are often shown to be linked to higher invertebrate abundance and diversity, but a number of studies have demonstrated, however, that this is not always the case. The objective of this study was to analyze the effects of four macrophyte species with two contrasting architectures (simple architecture with broad leaves: Vallisneria spiralis L. and Potamogeton malaianus Miq. and complex architecture with finely dissected leaves: Ceratophyllum demersum L. and Myriophyllum verticillatum L.) on zooplanktons. We hypothesized that structurally more complex macrophytes would support more zooplanktons and higher diversity, species richness, abundance and biomass, and to test our hypotheses, zooplankton samples within the above-mentioned macrophytes were collected to analyze the variances at different times. Contrary to our expectations, we found that the zooplankton' responses were independent to the macrophyte architecture. Specially, although finely dissected M. verticillatum could significantly increase total zooplanktons, diversity, species richness, rotifers and cladocerans than the other three macrophytes, the effects of finely dissected $C$. demersum on these parameters exhibited no significant differences compared to two broad leaved macrophytes ( $V$. spiralis and $P$. malaianus). Moreover, broad leaved macrophytes even increased more abundance zooplanktons than finely dissected $C$. demersum. In addition, the effects of macrophytes on zooplanktons also varied with zooplankton species. For example, the four tested macrophytes could significantly increase cladoceran abundance and biomass. Yet for copepods, the density was significantly increased in presence of $V$. spiralis and $C$. demersum, but $P$. malaianus and $M$. verticillatum did not show significant effects on copepod density. Moreover, all the tested macrophytes except for $V$. spiralis even significantly suppress copepod biomass. Therefore, our results did not support the hypothesis that structurally complex macrophytes harbor more zooplanktons, and showed that the effects of the investigated macrophytes on zooplanktons were not likely to depend on their architectures, but seemed to rely on complex relationships between macrophyte and zooplankton species.
\end{abstract}

Key words: Diversity; richness; cladoceran; copepod.

Received: May 2016. Accepted: May 2017.

\section{INTRODUCTION}

Habitat complexity in the freshwater ecosystem plays an important role in the growth and distribution of aquatic organisms (Meerhoff et al., 2007; Debastiani-Júnior et al., 2016). Generally, animal abundance and species richness are considerably higher where submerged macrophytes are present (Hemminga and Duarte, 2000). Macrophytes are an important habitat component in shallow lakes, as complex macrophyte architecture of dissected leaves and stems often supports more macroinvertebrate populations (Xie et al., 2006; Hinojosa-Garro et al., 2010). It is well established that macrophytes with finely dissected leaves provide more advantages (shelter against predation, food resources and cover or substrate) for the growth and reproduction of invertebrates than do macrophytes with broad leaves (Warfe and Barmuta, 2006; Vermonden et al., 2012). The increased surface area of macrophytes with dissected leaves is more suited to colonization by large numbers of invertebrates, augmenting the species richness in freshwater ecosystems (Heino, 2005; Renniie and Jackson, 2005). Indeed, the increase in habitats, spawning places, and numbers of some invertebrate species living on dissected leaved macrophytes is enough to decrease the risk of extinction. In addition, the complex architecture of macrophytes provides more cover from predators, resulting in increased population density of aquatic invertebrates (Vermonden et al., 2009, 2012). The theoretical support for the aforementioned benefits mostly hinges upon on the reasoning that macrophyte surface area and spatial heterogeneity increase with leaf dissection.

However, the relationship that complex macrophyte habitats support higher animal abundance and biomass is not always found (Soszka, 1975; Cry and Downing, 1988; Taniguchi et al., 2003; Cremona et al., 2008). Soszka (1975) reported that Myriophyllum verticillatum L. with 
dissected leaves supported fewer invertebrates than the other 12 macrophytes with dissected and broad leaves, and Ceratophyllum demersum L. and Utricularia sp. with dissected leaves did not sustain significantly more invertebrates than broad-leaved macrophytes. Moreover, broad-leaved macrophytes sometimes have also been found to support more invertebrates than dissected leaved macrophytes. For example, more invertebrates were reported in Potamogeton amplifolius Tuckerm than in P. rohbinsii Oakes or Vallisneria spiralis L. Stands (Cry and Downing, 1988). Taniguchi (2003) also stated that there was no difference in the abundance of invertebrates between simple and complex forms on the natural macrophytes. Therefore, submerged macrophytes with a complex architecture did not always host significantly greater macroinvertebrate biomass than plants with a simpler architecture (Cremona et al., 2008).

Thus, the hypothesis that submerged macrophytes with complex architectures support higher invertebrate abundance than macrophytes with simple architectures requires additional empirical studies for verification. In this study, four submerged macrophytes with two contrasting architectures (finely dissected = complex architecture and broad-leaved $=$ simple architecture) and zooplankton community were selected to evaluate the effects of macrophyte architectures on zooplanktons.

\section{METHODS}

\section{Experimental design}

For this experiment, 15 pottery pots (diameter: $48 \mathrm{~cm}$; height: $36 \mathrm{~cm}$ ) were prepared in the laboratory with 12 pots for 4 test treatments and 3 pots for a control treatment. Each pot contained a $10-\mathrm{cm}$ high mixed sediment of sand and mud in a ratio of 1 to 1 , in which the sand was bought from the construction market and the mud was collected from the West Lake $\left(30^{\circ} 15^{\prime} \mathrm{N}, 120^{\circ} 09^{\prime} \mathrm{E}\right)$ in Hangzhou, China. This lake is one of the most famous lakes in China and was listed in UNESCO'S World Culture Heritage catalogue in 2011. After tap water was injected into the 15 pots, they were allowed to precipitate for 3 days to reduce the turbidity caused by watering.

Four submerged macrophytes (broad leaved: V. spiralis and Potamogeton malaianus Miq.; finely dissected: C. demersum and $M$. verticillatum) were also collected by an iron clamp and carefully cleaned to remove attaching organisms in the West Lake. Moreover, 15 experimental zooplankton samples collecting from this lake were gained respectively by filtering $100 \mathrm{~L}$ of water through a $112-\mu \mathrm{m}$ plankton net and concentrating it into a $100-\mathrm{mL}$ volume of plastic bottle. Individuals of the four macrophytes in analysis with nearly the same mean biomass of $150 \mathrm{~g}$, were planted in triplicate into 12 pots, but no macrophyte was planted in the control group. After 15 zooplankton samples were added to the 15 pots one by one, they were collected every 10 days during the later next 60 days to analyze the changes in zooplankton community.

\section{Sampling and data analysis}

Zooplankton samples in the pots were obtained by concentrating $1 \mathrm{~L}$ of water fixed with $9 \mathrm{~mL}$ Lugol's solution to $30 \mathrm{~mL}$ in a $50-\mathrm{mL}$ plastic bottle. Then, a $1 \mathrm{~mL}$ subsample was collected using a graduated pipette into a count-frame, and quantified using a $200 \times$ magnification inverted microscope (Olympus CKX31). Zooplanktons were identified to genus/species level using the standard reference keys of Wang (1961), Chiang and Du (1979), and Shen and Tai (1979).

All data were tested for normality with a ShapiroWilks test. Significant differences among total zooplankton, Shannon diversity index, species richness and three zooplankton groups (e.g., rotifer, cladoceran, and copepod) living among four macrophytes were determined using a one-way analysis of variance (ANOVA), and Duncan's multiple-range test was applied to explore the significant effects of four macrophytes on these parameters. All these analyses were completed using SPSS 21.0 for Microsoft Windows.

\section{RESULTS}

\section{Variance in zooplankton community composition on four macrophytes}

The analyses of zooplankton samples collected in the West Lake showed that the zooplankton community were consisted of rotifers and copepods, occupying $91.5 \%$ and $8.5 \%$ of zooplankton density $\left(43,920\right.$ ind $\left.\cdot \mathrm{L}^{-1}\right)$, respectively (Tab. 1). Among rotifers, copepods and nauplius,

Tab. 1. Density and proportion of dominant species in the zooplankton sample collected in the West Lake.

\begin{tabular}{lcc} 
Taxa & Density $\left(\right.$ ind $\cdot \mathrm{L}^{-1}$ ) & Proportion \\
Rotifer & & \\
Anuraeopsis fissa (Gosse) & 29,640 & $67.5 \%$ \\
Synchaeta stylata (Wierzejski) & 2640 & $6 \%$ \\
Polyarthra trigla (Ehrenberg) & 720 & $1.6 \%$ \\
Synchaeta oblonga (Ehrenberg) & 1200 & $2.7 \%$ \\
Keratella cochlearis (Gosse) & 1200 & $2.7 \%$ \\
Trichocerca pusilla (Lauterborn) & 720 & $1.6 \%$ \\
Rotaria rotatoria (Pallas) & 840 & $1.9 \%$ \\
Chromogaster sp. (Lauterborn) & 720 & $1.6 \%$ \\
Pompholyx sulcata (Hudson) & 480 & $1.1 \%$ \\
Others (<1\%) & 2040 & $4.7 \%$ \\
\hline Copepoda & & \\
Nauplius & 3720 & $8.5 \%$ \\
\hline
\end{tabular}


the dominant species were Anuraeopsis fissa (Gosse) (67.5\%), Synchaeta stylata (Wierzejski) (6\%), S. oblonga (Ehrenberg) (2.7\%), Keratella cochlearis (Gosse) $(2.7 \%)$, and nauplius $(8.5 \%)$, respectively. However, we have not found cladoceran and copepod adults, probably due to the high predation pressure existing in the West Lake.

During the experiment, all the zooplankton community groups in all the macrophyte treatments in analysis exhibited drastic changes. Nevertheless, the community structures tended to be almost stable from the $40^{\text {th }}$ day to the $60^{\text {th }}$ day (Fig. 1). The results in the stable state showed that cladocerans and copepods were found to occupy $40 \%$ and $60 \%$ of zooplankton density in $V$. spiralis, approximately $60 \%$ and $40 \%$ in P. malaianus, $44 \%$ and $56 \%$ in control, $40 \%$ and $60 \%$ in C. demersum, $80 \%$ and $10 \%$ in $M$. verticillatum treatments, respectively. However, rotifers have completely missed in control (Fig. 1A), V.spiralis (Fig. 1D), P. malaianus (Fig. 1E) and C. demersum (Fig. 1C) treatments, but some species were found in $M$. verticillatum treatment occupying about $10 \%$ of zooplankton density (Fig. 1B). Moreover, in the stable state the dominant species in the five treatments had changed into Alona karua (King), Chydorus sphaericus (O.F. Müeller), Pleuroxus trigonellus (O.F. Müller), Thermocyclops taihokuensis (Harada), and nauplius (Tab. 2).

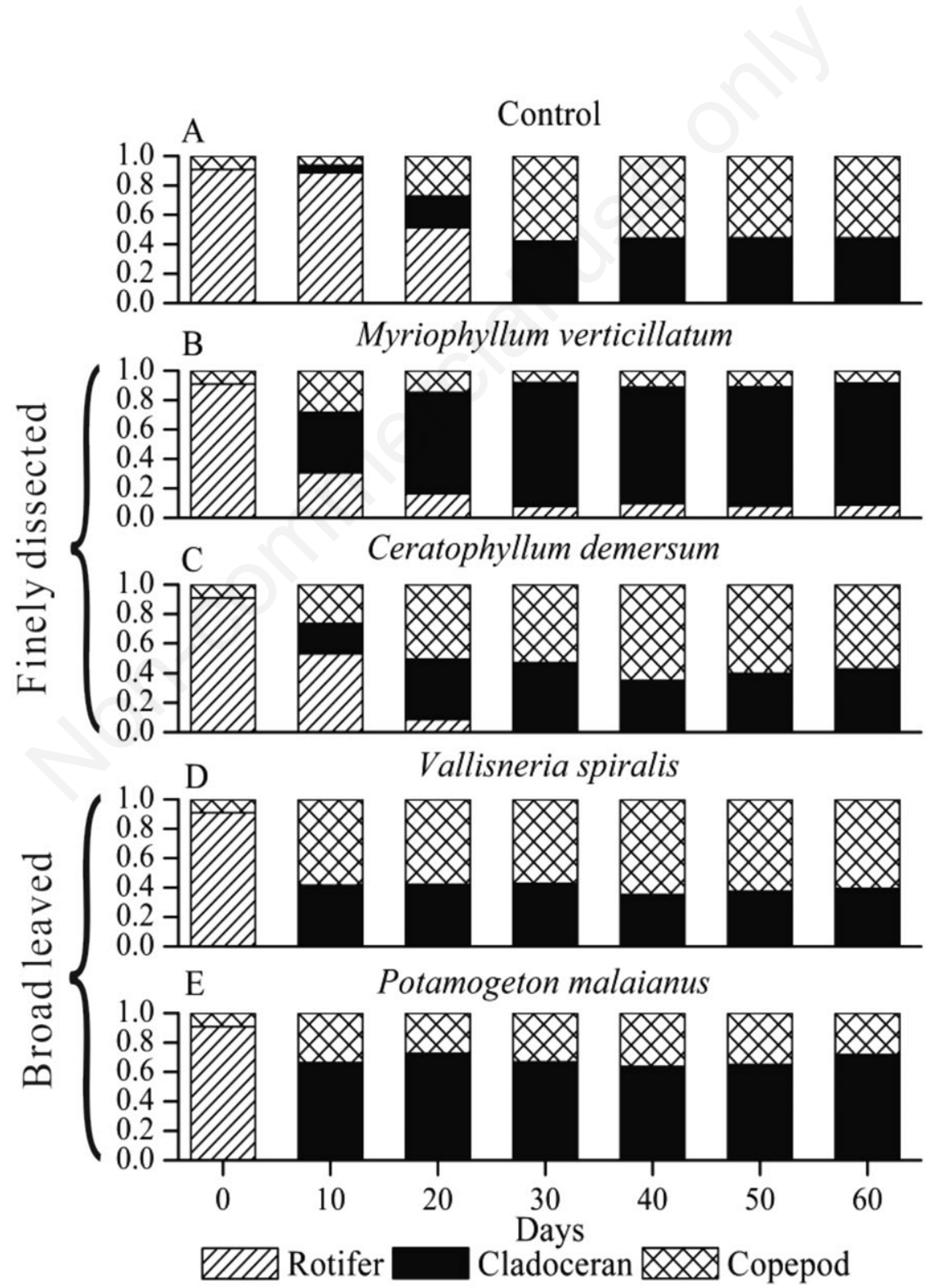

Fig. 1. Variance in the proportion of rotifers, cladocerans, and copepods from day 10 to 60, in five groups: A) control: B) Myriophyllum verticillatum L.; C) Ceratophyllum demersum L.; D) Vallisneria spiralis L.; E) Potamogeton malaianus Miq. 


\section{Variance in zooplankton parameters in five groups}

During the whole period of investigation, the variances of zooplankton parameters in all the five treatments in analysis exhibited two distinct change trends: 1) a continuous stable state; or 2) a biphasic trend characterized by significant variations from the $10^{\text {th }}$ day to the $30^{\text {th }}$ day (period 1 ), followed by a stable state from the $40^{\text {th }}$ day to the $60^{\text {th }}$ day (period 2) (Fig. 2 and Tab. 3). Specially, zooplankton parameters in the two broad-leaved macrophyte treatments ( $V$. spiralis and $P$. malaianus) had been in a stable state during the whole period (Tab. 3). Conversely, in the control group they significantly decreased in period 1 , but tended to be stable in period 2. However, the zooplankton parameters in the two finely dissected macrophyte treatments $(C$. demersum and $M$. verticillatum) exhibited different change trends (Tab. 3 and Fig. 2). In the C. demersum treatment, cladocerans, copepods, total zooplankton biomass and diversity were in a stable state during the whole period. On the contrary, rotifers, total zooplankton density and species richness changed significantly in period 1 , but were in a stable state in period 2 (Tab. 3). For zooplankton in presence of $M$. verticillatum, rotifers and copepods were also in a stable state in the whole period (Fig. 2 E-F,I-J). Yet, total zooplankton and cladocerans significantly increased (Fig. 2 A-B,G-H), but diversity and richness drastically decreased in period 1 (Fig. 2 C-D). Moreover, all of them were in a stable state in period 2.

\section{Analyzing the effects of macrophyte architectures on zooplanktons}

As all of the zooplankton parameters in the five treatments were in a stable state on the $40^{\text {th }}$ day, the variance analysis of zooplankton on the $40^{\text {th }}$ day may be utilized to highlight the effects of macrophyte architecture on zooplankton. The obtained results showed that the architecture seemed to have no significant effects on total zooplankton, diversity and richness (Fig. 3). Specially, finely dissectedleaved $M$. verticillatum could support more total zooplankton and higher species diversity and species richness than the other three macrophytes. Hence, the finely dissectedleaved $C$. demersum exhibited no significant effects on total zooplankton biomass, diversity and richness, and even lesser effects on total zooplankton density compared to the two broad-leaved macrophytes ( $V$. spiralis and $P$. malaianus).

The architecture also seemed to have no significant effects on three main zooplankton groups (e.g., rotifer, cladoceran and copepod) (Fig. 4). For the rotifers, significant variances in the density and biomass were only found at $M$. verticillatum treatments with complex architecture and, no significant variances existed at the three remaining treatments, the broad-leaved macrophytes ( $V$. spiralis and $P$. malaianus) and the complex $C$. demersum (Fig. 4A). Moreover, the effects of macrophytes on density and biomass of cladocerans were also independent on macrophyte architecture, as for rotifers (Fig. 4B). In general, all macrophytes could encourage cladocerans, but only $M$. verticillatum showed significant effects on rotifers. For the copepods, macrophytes could provide various effects on density and biomass (Fig. 4C). Specially, the broad-leaved P. malaianus and the finely dissected $M$. verticillatum did not show more effects on copepod density than control group; on the contrary, $V$. spiralis and $M$. verticillatum supported higher density than the other three groups. Yet, except for $V$. spiralis, all of the other three macrophytes could significantly decrease copepod biomass.

Tab. 2. Distribution of dominant species in the period 2 in the different five treatments tested: control, Ceratophyllum demersum L. (Cer_dem), Myriophyllum verticillatum L. (Myr_spi), Vallisneria spiralis L. (Val_spi) and Potamogeton malaianus Miq. (Pot_mal).

\begin{tabular}{|c|c|c|c|c|c|}
\hline Taxa & Control & Cer_dem & Myr_spi & Val_spi & Pot_mal \\
\hline \multicolumn{6}{|l|}{ Rotifer } \\
\hline Colurella uncinata (O.F. Muller) & & & + & & \\
\hline Monostyla sp. (Ehrenberg) & & & + & & \\
\hline Trichocerca sp. (Lamarck) & & & + & & \\
\hline \multicolumn{6}{|l|}{ Cladoceran } \\
\hline Alona karua (King) & + & + & ++ & + & + \\
\hline Alona eximia (R.W. Kiser) & & + & + & & \\
\hline Chydorus sphaericus (O.F. Mueller) & + & & ++ & & \\
\hline Alona guttata (G.O. Sars) & & & + & + & + \\
\hline Pleuroxus hamulatus (Birge) & & & ++ & + & \\
\hline Pleuroxus trigonellus (O.F. Müller) & + & + & + & + & + \\
\hline Pleuroxus denticulatus (Birge) +++ & & & & & \\
\hline \multicolumn{6}{|l|}{ Copepoda } \\
\hline Thermocyclops taihokuensis (Harada) & + & + & + & & + \\
\hline Sinocalanus dorrii (Brehm) & + & + & & + & \\
\hline Nauplius & + & + & + & + & + \\
\hline
\end{tabular}




\section{DISCUSSION}

Which is more important: macrophyte species or architecture?

The effect of macrophyte architecture on zooplankton community seemed to be very limited in this study. Our results showed that only $M$. verticillatum could signifi- cantly support more zooplanktons and higher diversity and species richness; whereas the other three macrophytes almost showed no significant differences compared to the control conditions. Even broad-leaved V. spiralis and $P$. malaianus could support higher zooplankton density than finely dissected-leaved $C$. demersum. Moreover, we also found that only finely dissected-leaved $M$. verticillatum provided more advantages for cladocerans than the two
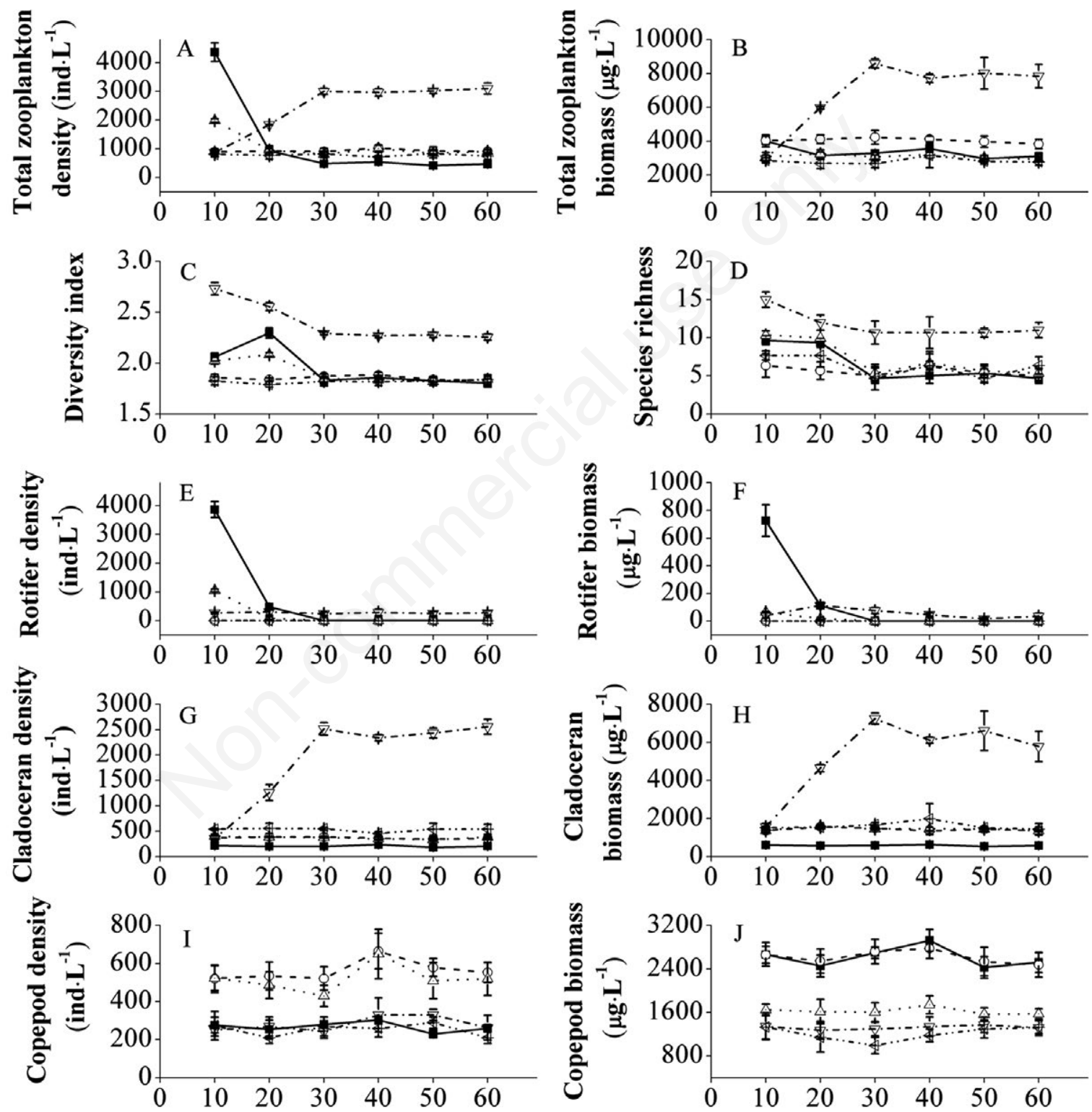

\section{- Control $-\bigcirc-$ Vallisneria spiralis $\cdots \triangle$ Ceratophyllum demersum - - Myriophyllum verticillatum - \$.Potamogeton malaianus}

Fig. 2. Variances in mean density and biomass $( \pm \mathrm{SE})$ of total zooplankton (A-B), diversity index (C), species richness (D) and three zooplankton groups - rotifer (E-F), cladoceran (G-H), and copepod (I-J) - in five groups (control, Ceratophyllum demersum L., Myriophyllum verticillatum L., Vallisneria spiralis L. and Potamogeton malaianus Miq.) from day 10 to day 60. 
broad-leaved macrophytes ( $V$. spiralis, and P. malaianus), but $C$. demersum did not support cladocerans largely than does broad-leaved macrophytes. These results do not support the hypothesis that submerged macrophytes with complex architecture should have a more abundance and biomass of zooplankton than macrophytes with simple morphology, indicating that macrophyte architecture may not be a good indicator of zooplankton abundance or biomass. This conclusion was also consistent with the results of many other studies (Lalonde and Downing, 1992; Cremona et al., 2008; Hansen et al., 2010). For example, Cremona et al. (2008) reported that submerged macrophytes with a complex architecture did not host significantly greater macroinvertebrate biomass than macrophytes with a simpler architecture. Hansen (2010) also did not find significant variances in invertebrate abundance on morphologically more complex macrophytes (M. spicatum and Chara baltica Bruzelius) than on the structurally simpler

Tab. 3. A one-way analysis of variances (ANOVA) of community parameters (species diversity, species richness, abundance and density) of total zooplankton, and the density and biomass of three zooplankton groups (rotifer, cladoceran, and copepod) in five groups (control, Ceratophyllum demersum L., Myriophyllum verticillatum L., Vallisneria spiralis L. and Potamogeton malaianus Miq.) over time.

\begin{tabular}{|c|c|c|c|c|c|c|c|c|c|}
\hline & \multicolumn{3}{|c|}{ Period 1} & \multicolumn{3}{|c|}{ Period 2} & \multicolumn{3}{|c|}{ Whole period } \\
\hline & Df & $\mathbf{F}$ & $\mathbf{P}$ & Df & $\mathbf{F}$ & $\mathbf{P}$ & Df & $\mathbf{F}$ & $\mathbf{P}$ \\
\hline \multicolumn{10}{|l|}{ Control group } \\
\hline Total zooplankton density & 8 & 297 & $* *$ & 8 & 3.6 & 0.09 & 17 & 312 & $* *$ \\
\hline Total zooplankton biomass & 8 & 10.58 & $* *$ & 8 & 2.94 & 0.13 & 17 & 8.28 & $* *$ \\
\hline Diversity index & 8 & 23.44 & $* *$ & 8 & 0.6 & 0.58 & 17 & 10.89 & $* *$ \\
\hline Species richness & 8 & 8.87 & $*$ & 8 & 1.89 & 0.23 & 17 & 21.89 & $* *$ \\
\hline Rotifer density & 8 & 484 & $* *$ & & - & - & 17 & 525 & $* *$ \\
\hline Rotifer biomass & 8 & 104 & $* *$ & & - & - & 17 & 116 & $* *$ \\
\hline Cladoceran density & 8 & 0.32 & 0.74 & 8 & 8.42 & $*$ & 17 & 1.63 & 0.23 \\
\hline Cladoceran biomass & 8 & 0.68 & 0.54 & 8 & 6.61 & $*$ & 17 & 2.31 & 0.11 \\
\hline Copepod density & 8 & 0.45 & 0.66 & 8 & 9.92 & $*$ & 17 & 2.09 & 0.14 \\
\hline Copepod biomass & 8 & 1.58 & 0.28 & 8 & 5.55 & $*$ & 17 & 2.96 & 0.06 \\
\hline \multicolumn{10}{|l|}{ Vallisneria spiralis } \\
\hline Total zooplankton density & 8 & 0.12 & 0.89 & 8 & 1.07 & 0.4 & 17 & 0.78 & 0.58 \\
\hline Total zooplankton biomass & 8 & 0.26 & 0.78 & 8 & 0.91 & 0.45 & 17 & 0.66 & 0.66 \\
\hline Diversity index & 8 & 0.86 & 0.47 & 8 & 0.93 & 0.45 & 17 & 1.94 & 0.16 \\
\hline Species richness & 8 & 1.52 & 0.29 & 8 & 2.96 & 0.13 & 17 & 0.72 & 0.62 \\
\hline Cladoceran density & 8 & 0.8 & 0.49 & 8 & 0.27 & 0.77 & 17 & 1.32 & 0.32 \\
\hline Cladoceran biomass & 8 & 3.67 & 0.09 & 8 & 0.42 & 0.68 & 17 & 1.95 & 0.16 \\
\hline Copepod density & 8 & 0.02 & 0.98 & 8 & 1.37 & 0.32 & 17 & 1.2 & 0.37 \\
\hline Copepod biomass & 8 & 0.28 & 0.76 & 8 & 1.52 & 0.29 & 17 & 0.63 & 0.68 \\
\hline \multicolumn{10}{|l|}{ Ceratophyllum demersum } \\
\hline Total zooplankton density & 8 & 121 & $* *$ & 8 & 1.96 & 0.22 & 17 & 61.37 & $* *$ \\
\hline Total zooplankton biomass & 8 & 0.49 & 0.64 & 8 & 2.31 & 0.18 & 17 & 0.91 & 0.51 \\
\hline Diversity index & 8 & 0.64 & 0.56 & 8 & 0.37 & 0.71 & 17 & 0.54 & 0.75 \\
\hline Species richness & 8 & 26.38 & $* *$ & 8 & 1.44 & 0.31 & 17 & 17.32 & $* *$ \\
\hline Rotifer density & 8 & 621 & $* *$ & & - & - & 17 & 653 & $* *$ \\
\hline Rotifer biomass & 8 & 146 & $* *$ & & - & - & 17 & 175 & $* *$ \\
\hline Cladoceran density & 8 & 0.7 & 0.54 & 8 & 2.64 & 0.15 & 17 & 2.26 & 0.08 \\
\hline Cladoceran biomass & 8 & 3.75 & 0.09 & 8 & 0.54 & 0.61 & 17 & 1.72 & 0.2 \\
\hline Copepod density & 8 & 0.98 & 0.43 & 8 & 1.63 & 0.27 & 17 & 1.75 & 0.2 \\
\hline Copepod biomass & 8 & 0.05 & 0.96 & 8 & 1.74 & 0.25 & 17 & 0.52 & 0.76 \\
\hline \multicolumn{10}{|l|}{ Myriophyllum verticillatum } \\
\hline Total zooplankton density & 8 & 395 & $* *$ & 8 & 0.67 & 0.55 & 17 & 170 & $* *$ \\
\hline Total zooplankton biomass & 8 & 574 & $* *$ & 8 & 1.19 & 0.37 & 17 & 48.62 & $* *$ \\
\hline Diversity index & 8 & 82 & $*$ & 8 & 0.48 & 0.64 & 17 & 97.57 & $* *$ \\
\hline Species richness & 8 & 10 & $* *$ & 8 & 0.06 & 0.94 & 17 & 5.28 & $*$ \\
\hline Rotifer density & 8 & 0.59 & 0.58 & 8 & 0.2 & 0.87 & 17 & 0.28 & 0.92 \\
\hline Rotifer biomass & 8 & 175 & 0.84 & 8 & 3.45 & 0.1 & 17 & 2.24 & 0.12 \\
\hline Cladoceran density & 8 & 236 & $* *$ & 8 & 3.06 & 0.12 & 17 & 185 & $* *$ \\
\hline Cladoceran biomass & 8 & 472 & $* *$ & 8 & 0.9 & 0.46 & 17 & 39.6 & $* *$ \\
\hline Copepod density & 8 & 0.37 & 0.7 & 8 & 1.01 & 0.42 & 17 & 1.53 & 0.25 \\
\hline Copepod biomass & 8 & 0.11 & 0.9 & 8 & 0.08 & 0.92 & 17 & 0.13 & 0.98 \\
\hline
\end{tabular}

Period 1, days 10 to 30 ; period 2 , days 40 to 60 ; whole period, days 10 to $60 . * * P<0.01 ; * P<0.05$. 
plant (Potamogeton perfoliatus L.). Consequently, the relationship between structural complexity of macrophytes and zooplankton abundance or biomass is itself complex, and does not always respond to general predictions.

In addition, other factors besides macrophyte architecture (such as, different allelochemicals from diverse macrophytes) could mediate the zooplankton community in macrophyte habitats. In this study, cladoceran density and biomass in all macrophyte treatments were higher than those in the control treatment, indicating that four macrophytes were conducive to the cladoceran growth. Moreover, $M$. verticillatum supported more cladocerans than the other three macrophytes, but the effects of the three macrophytes on cladocerans were not significant. The architecture seemed to have no significant effects on facilitating cladocerans between four macrophytes. Some studies also found that macrophytes with a similar architecture did not always exhibit similar effects on some organisms. For example, Kairesalo (1983) reported that simple structural Vallisneria americana Michx with its long and narrow, tape-shaped leaves, allowed more light penetration and nutrient exchange, thus favoring periphyton growth, and then supported sometimes larger communities of gastropods than Potamogeton species with similar architecture. Furthermore, macrophyte species characteristic seemed to exert stronger effects on some aquatic organisms than macrophyte architecture. Additionally, greater water circulation in $V$. americana stands could guarantee other critical conditions for macroinvertebrates like higher dissolved oxygen levels than other macrophytes (Caraco and Cole, 2002). In addition, allelochemicals releasing from macrophytes decreased survival or changed behaviors of some invertebrate taxa (dipteran larvae, Dhillon et al., 1982; mysids, Lindén and Lehtiniemi, 2005), but the concentration and effectiveness of such substances varied with macrophyte species. Gross (2003) reported that allelopathic substances have been documented for M. spicatum but, are rare among submerged Potamogeton species. Therefore, macrophyte-specific allelopathic influences on some aquatic organisms also seemed to be independent of macrophyte architecture.

Based on the above analysis, compared to macrophyte architectures, macrophyte species characteristics seemed to be more important, and exhibit stronger effects on zooplanktons in this study.

\section{Effects of macrophytes on zooplankton species}

In this study, the appearances of cladocean and copepod adults are probably caused by the suitable environment condition, which is beneficial to the germination of their dor-

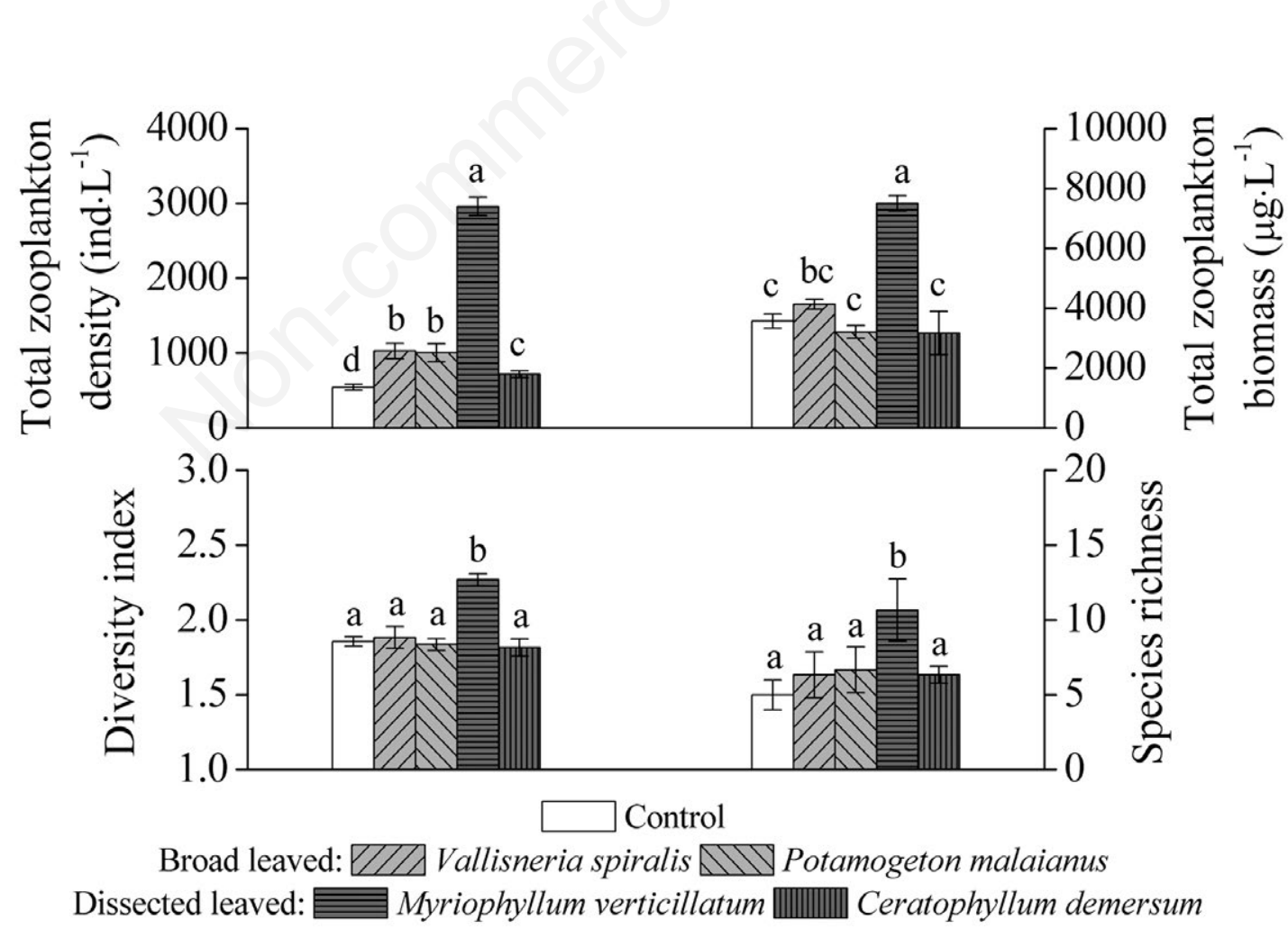

Fig. 3. Variance in mean density and biomass $( \pm \mathrm{SD})$ of total zooplankton, diversity index and species richness in five groups (control, Vallisneria spiralis L., Potamogeton malaianus Miq., Myriophyllum verticillatum L. and Ceratophyllum demersum L.) in the $40^{\text {th }}$ day $(\mathrm{n}=3)$. Bars with identical lowercase letters indicate no significant differences $(\mathrm{P}>0.05)$, while bars with different letters indicate significant differences $(\mathrm{P}<0.05)$. 
mant eggs in the mud. Coupled with a very low predation pressure, they can dominate zooplankton community in this study (De los Ríos-Escalante, 2015). Moreover, the effects of macrophyte architectures on three dominant zooplankton groups were not always consistent. Specially, all macrophytes significantly increased cladocerans, but only $M$. verticillatum supported more rotifers. For copepods, V. spiralis and $C$. demersum increased density, but P. malaianus, $M$. verticillatum and $C$. demersum showed significant inhibitions on their biomass. These different effects of macrophytes on zooplanktons seemed to mostly depend on zooplankton species and not on macrophyte architecture. Many studies have also confirmed that the preferences of different organisms to submerged macrophytes are different (Lalonde and Downing, 1992; Kuczynska-Kippen and Cerbin, 2003; Cerbin et al., 2007; Cremona et al., 2008).
For example, Kuczynska-Kippen and Cerbin (2003) found that the periphyton from $M$. verticillatum has the higher biomass than those from Chara and Typha. Greater macroinvertebrate (e.g., gastropods) biomass sometime appeared on macrophytes with a simpler architecture than macrophytes with a complex architecture (Lalonde and Downing, 1992), and this could be related to substrate preferences of Gastropoda toward the tape grass $V$. americana (Cremona et al., 2008). Daphnia magna is unlikely to prefer to M. verticillatum than other macrophytes because of maturing at a smaller size and producing fewer eggs under the influence of $M$. verticillatum (Cerbin et al., 2007). Therefore, various organisms exhibited different responses and preferences on different macrophytes, and these responses and preferences might mostly depend on organism species rather than on macrophyte architecture.

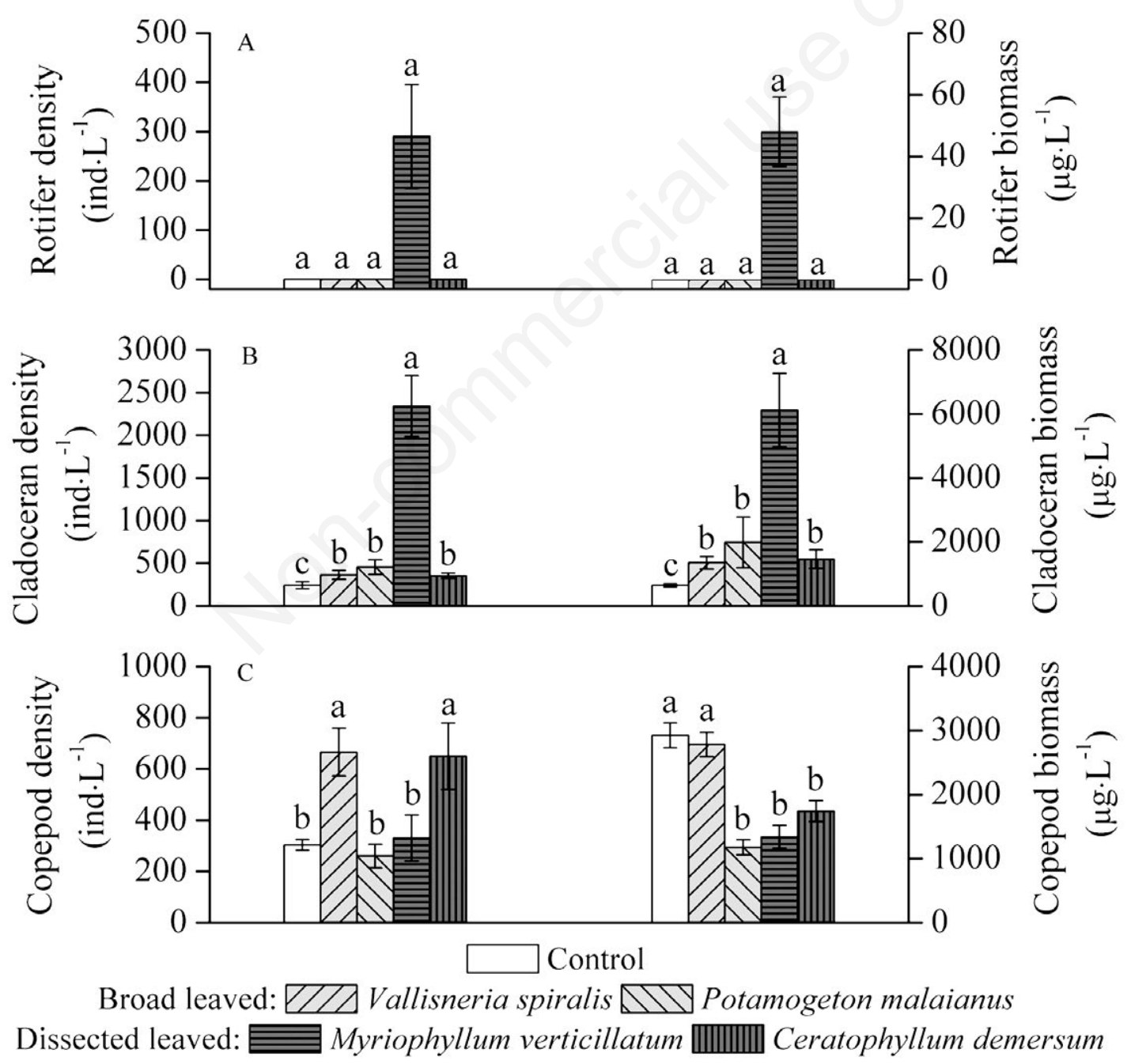

Fig. 4. Variance in mean density and biomass $( \pm \mathrm{SD})$ of three zooplankton groups (rotifer (A), cladoceran (B) and copepod (C)) in five groups (control, Vallisneria spiralis L., Potamogeton malaianus Miq., Myriophyllum verticillatum L. and Ceratophyllum demersum L. ) in the day $40^{\text {th }}(\mathrm{n}=3)$. Bars with identical lowercase letters indicate no significant differences $(\mathrm{P}>0.05)$, while bars with different letters indicate significant differences $(\mathrm{P}<0.05)$. 
In addition, during the stable state (day 40 to 60; period 2) rotifers were almost disappeared or at a low level in all the conditions tested, and large-sized zooplankton (e.g., cladocerans and copepods) dominated the community. These results indicated that cladocerans and copepods owned stronger competitive advantages than rotifers in this study, as confirmed by many previous studies (Gilbert, 1988; Lampert and Sommer, 1997). For example, Lampert and Sommer (1997) determined that cladocerans with a larger body size could gather food more efficiently from the medium, resulting in the starvation of rotifers. Kirk (1997) also found that larger cladocerans had more advantages in resisting starvation over smaller rotifers and thus survived for a longer time under a foodlimited condition. However, some rotifer species still existed in M. verticillatum, not in C. demersum in period 2, indicating that the species characteristic of $M$. verticillatum might support some rotifer species other than its finely dissected structure.

\section{CONCLUSIONS}

In this study, our results did not support the hypothesis that submerged macrophytes with complex architecture support more zooplanktons than simple structural macrophytes, and we found that macrophyte architecture is not a good predictor of abundance and biomass of zooplankton. The variances in promotions of $C$. demersum with complex architecture on cladocerans were not significant with two macrophytes with simple architecture. Moreover, broad-leaved P. malaianus and two dissected-leaved macrophytes could even significantly suppress copepod biomass. Therefore, the effects of submerged macrophytes on zooplanktons mainly depend on macrophyte speciescharacteristics and zooplankton species rather than on macrophyte architecture.

\section{ACKNOWLEDGMENTS}

This study was supported by Major Science and Technology Program for Water Pollution Control and Treatment of China 12 $2^{\text {th }}$ Five-Year Plan (No. 2012ZX07101007-005), National Natural Science Foundation of China (No. $51178452,51208498,51308530)$. We would like to thank Drs. Dong Xu and Enrong Xiao for their valuable comments and advice. Thanks are also given to other laboratory colleagues for field and laboratory work assistance.

\section{REFERENCES}

Caraco NF, Cole JJ, 2002. Contrasting impacts of a native and alien macrophyte on dissolved oxygen in a large river. Ecol. Appl. 12:1496-1509.
Cerbin S, Donk EV, Gulati RD, 2007. The influence of Myriophyllum verticillatum and artificial plants on some life history parameters of Daphnia magna. Aquat. Ecol. 41:263-271.

Chiang S, Du N, 1979. Fauna Sinica. Crustacea. Freshwater Cladocera. Science Press, Beijing: 297 pp.

Cremona F, Planas D, Lucotte M, 2008. Biomass and composition of macroinvertebrate communities associated with different types of macrophyte architectures and habitats in a large fluvial lake. Fund. Appl. Limnol. 171/2:119-130.

Cry H, Downing JA, 1988. The abundance of phytophilous invertebrates on different species of submerged macrophytes. Freshwater. Biol. 20:365-374.

De los Ríos-Escalante P, 2015. Fish predation effects on body length of planktonic cladocerans and copepods in Chilean lakes. Crustaceana 88:1193-1199.

Debastiani-Júnior JR, Elmoorloureiro LM, Nogueira MG, 2016. Habitat architecture influencing microcrustaceans composition: A case study on freshwater Cladocera (Crustacea Branchiopoda). Braz. J. Biol. 76:93-100.

Dhillon MS, Mulla MS, Hwang YS, 1982. Allelochemics produced by the hydrophyte Myriophyllum spicatum affecting mosquitoes and midges. J. Chem. Ecol. 8:517-26.

Gilbert JJ, 1988. Suppression of rotifer populations by daphnia: a review of the evidence, the mechanisms, and the effects on zooplankton community structure. Limnol. Oceanogr. 33:1286-1303.

Gross EM, 2003. Allelopathy in aquatic autotrophs. Crit. Rev. Plant. Sci. 22:313-339.

Hansen JP, Sagerman J, Wikström SA, 2010. Effects of plant morphology on small-scale distribution of invertebrates. Mar. Biol. 157:2143-2155.

Heino J, 2005. Functional biodiversity of macroinvertebrate assemblages along major ecological gradients of boreal headwater streams. Freshwater Biol. 50:1578-1587.

Hemminga MA, Duarte CM, 2000. Seagrass ecology. Cambridge University Press, Cambridge: 298 pp.

Hinojosa-Garro D, Mason CF, Underwood GJC, 2010. Influence of macrophyte spatial architecture on periphyton and macroinvertebrate community structure in shallow water bodies under contrasting land management. Fund. Appl. Limnol. 177:19-37.

Kairesalo T, 1983. Dynamics of epiphytic communities on Equisetum fluviatile L., p. 153-160. In: R.G. Wetzel (ed.), Periphyton of freshwater ecosystems. Springer, Dordrecht.

Kirk KL, 1997. Life-history responses to variable environments: starvation and reproduction in planktonic rotifers. Ecology 78:434-441.

Kuczynska-Kippen N, Cerbin S, 2003. Diurnal changes in horizontal distribution of rotifers and crustaceans of apolymictic lake. Ekol. Bratislava 22:248-256.

Lampert W, Sommer U, 1997. Limnoecology: The ecology of lakes and streams. Oxford University Press, New York: $382 \mathrm{pp}$.

Lalonde S, Downing JA, 1992. Phytofauna of eleven macrophyte beds of differing trophic status, depth, and composition. Can. J. Fish. Aquat. Sci. 49:992-1000.

Lindén E, Lehtiniemi M, 2005. The lethal and sublethal effects of the aquatic macrophyte Myriophyllum spicatum on Baltic littoral planktivores. Limnol. Oceanogr. 50:405-411.

Meerhoff M, Clemente JM, Mello FTD, Iglesias C, Pedersen 
AR, Jeppesen E, 2007. Can warm climate-related structure of littoral predator assemblies weaken the clear water state in shallow lakes? Glob. Change Biol. 13:1888-1897.

Renniie MD, Jackson LJ, 2005. The influence of habitat complexity on littoral invertebrate distributions: patterns differ in shallow prairie lakes with and without fish. Can. J. Fish. Aquat. Sci. 62:2088-2099.

Shen C, Tai A, 1979. Fauna Sinica. Crustacea. Freshwater Copepoda. Science Press, Beijing: $450 \mathrm{pp}$.

Soszka GJ, 1975. The invertebrates on submerged macrophytes in three Masurian lakes. Ekol. Pol. 23:371-391.

Taniguchi H, Nakano S, Tokeshi M, 2003. Influences of habitat complexity on the diversity and abundance of epiphytic invertebrates on plants. Freshwater Biol. 48:718-728.

Vermonden K, Lerven RSEW, Van Der Velde G, Van Katwijk
MM, Roelofs JGM, Hendriks AJ, 2009. Urban drainage systems: An undervalued habitat for aquatic macroinvertebrates. Biol. Conserv. 142:1105-1115.

Vermonden K, Van Der Velde G, Leuven RSEW, 2012. Key factors for biodiversity of surface waters in climate proof cities. Resour. Conserv. Recy. 64:56-62.

Warfe DM, Barmuta A, 2006. Habitat structural complexity mediates food web dynamics in a freshwater macrophyte community. Oecologia 150:141-154.

Wang JJ, 1961. Freshwater rotifer fauna in China. Science Press, Beijing: 285 pp.

Xie ZC, Ma K, Liu R, Tao T, Jing C, Shu S, 2006. Effect of plant architecture on the structure of epiphytic macroinvertebrate communities in a Chinese lake. J. Freshwater Ecol. 21:131-137. 